\title{
SPATIAL DIFFERENTIATION CHARACTERISTICS OF ALPINE GRASSLAND PATCHES IN THE SOURCE REGION OF THE YELLOW RIVER AND ITS ECOLOGICAL SIGNIFICANCE
}

\author{
LIU Jia ${ }^{1.2}$, CHEN Jian-Jun ${ }^{1,2, *}$, ZHAO Xu-Ning ${ }^{1,2}$, ZHANG Hui-Zi ${ }^{1,2}$ \\ ${ }^{1}$ College of Geomatics and Geoinformation, Guilin University of Technology, Guilin 541000, China \\ 2695886266@qq.com (L.J.), chenjj@glut.edu.cn (C.J.), 1366910389@qq.com (Z.X), 448028541@qq.com (Z.H) \\ ${ }^{2}$ Guangxi Key Laboratory of Spatical Information and Geomatics, Guilin 541004, China
}

Commission VI, WG VI/4

KEY WORDS: Alpine grassland, Differentiated characteristics, Ecological indicators, Patch index, Landscape pattern

\begin{abstract}
:
The source region of the Yellow River is an important source of water conservation in the Qinghai-Tibet Plateau. It is also an animal husbandry base that has a major impact on China. Its ecological environment changes will have a major impact on the safe and sustainable development of water use in Asia. The alpine grassland is an important part of the ecosystem of the Yellow River source area, and the spatial differentiation characteristics of the plaque have important indication significance for the ecological environment succession. In this paper, the alpine grassland in the source region of the Yellow River is taken as the research object. Based on the aerial image of the unmanned aerial vehicle, the EGI threshold method is used to extract the vegetation patches and the bare plaques to obtain high-precision field monitoring data, and the landscape ecology principle is used to analyze the four types of alpine grassland. The morphological characteristics of plaques in different grassland types are studied, and the spatial indications of spatial sequences are used to study the ecological significance of plaque succession. The results show that the number of plaques in swamp meadows, alpine meadows, degraded meadows and alpine grassland increase significantly, the degree of fragmentation increase, and the area of vegetation patches decrease significantly. The area of bare plaque increase significantly as the main trend; the distribution and dominance of landscape plaques are analyzed; the swamp meadow have the highest spread, the best aggregation, and the largest proportion of vegetation plaque, the highest degree of dominance, alpine grassland Conversely; in terms of the complexity of landscape patch shape; the area-weighted shape index and the area-weighted fractal dimension increase with the order of swamp meadows, alpine meadows, degraded meadows and alpine grasslands, tending to be complex plaque space. The ecological risk intensity index of alpine grassland in the source region of the Yellow River varies greatly, and the ecological risk of alpine grassland is high. The results of this study provide data support for elucidating the mechanism of spatial differentiation of alpine grass plaques, provide scientific assistance for grassland monitoring and management in the source area, and it provides an important basis for further discussion on ecological system protection, animal husbandry economy and sustainable development of alpine grassland in China. At the same time, it provides important theoretical support and ecological indication significance for the understanding of the alpine grassland ecosystem succession in the source area of the Yellow River.
\end{abstract}

\section{INTRODUCTION}

Patches are the main parameters of landscape spatial structure, and are closely related to energy flow, material cycle, species and various ecological phenomena of ecosystem. Patch size, shape and distribution have important effects on animal migration, plant degradation and biodiversity distribution (Bolger, Alberts, 1991). Patch spatial differentiation is an important indicator of ecosystem evolution, which determines the spatial pattern and succession trend of ecosystem (Pan, Domon, 2001). Patches are ubiquitous in the alpine grassland of the Qinghai-Tibet Plateau. Studying the relationship between the spatial pattern of patches and ecological succession is the basis of reasonable protection of the Qinghai-Tibet Plateau.

In the study of patch spatial differentiation, the spatial analysis function, mathematical model and statistical analysis of ArcGIS technology are usually used to quantitatively analyze the spatial distribution characteristics of terrain objects in different regions (Li, 2018). Some scholars usually use some quantitative indicators of landscape ecology to reflect the spatial distribution and change characteristics of landscapes patches, such as Wang Xianli and others using GIS and landscape index to analyze the pattern of landscapes in Liaohe Delta, such as residential areas, rivers, wetlands and reservoirs (Wang, Xiao, 1997); Wei et al. took the Kanas tourist area in Xinjiang as the

\footnotetext{
${ }^{*}$ Corresponding author
} 
research area, and studied the vegetation landscape structure and pattern, the change of ecological carrying capacity, namely plant diversity, species diversity and soil content in the whole tourist area during human disturbance (Zheng, 2009). Combining with the current research on patches, most of them are based on the study of large-span spatial features. There are still many shortcomings in the small-scale study of grassland patches and bare land patches. Therefore, the study of patch succession has rich theoretical value and practical significance for ecological indicators. However, most of the studies on patch succession are based on theoretical models. For example, Sonia Kefi and other scholars used empty model, arid ecosystem model, mussel bed model and predator-prey model to study patch succession before ecosystem extinction (Kefi, Rietkerk, 2010). M.A. Irvine and other scholars applied the aggregation dynamics model to study the size distribution of vegetation patches (Irvine, Bull, 2015), and most of them lack high-precision measured data to verify the differentiation characteristics and succession of patches. In addition, most of the satellite images, such as Landsat and Spot, are used as data sources to identify patches by ArcGIS or ENVI fusion classification. However, due to the limitation of spatial and temporal resolution of satellite images, it is difficult to distinguish vegetation patches from bare land patches on the scale of satellite remote sensing, which brings some difficulties to the study of alpine grassland patch succession.

In view of this, this study takes the headwaters of the Yellow River in the Qinghai-Tibet Plateau as the research area. Four types of Alpine Grassland in the headwaters of the Yellow River are selected. The feasibility of patches is studied by UAV aerial photography. Based on the principle of EGI threshold method, vegetation patches and bare land patches are extracted, and space series is used to replace time. Sequence method is used to study the spatial differentiation characteristics of patches during grassland degradation, and FRAGSTATS software is used to analyze the ecological indicative significance of different landscape indices to measure patch succession, so as to promote the scientific management and ecological balance of alpine grassland in the source area of the Yellow River.

\section{MATERIALS AND METHOD}

\subsection{Survey of Research Areas}

As one of the three rivers sources, the source area of the Yellow River is the most important water conservation area in the Qinghai-Tibet Plateau of China (Zhao, Ma, 2011). Its geographical location is located in N33 $56 \sim 35$ 51', E95 $55 \sim 98$ 40 ', and the total area is about 2.54 The altitude of the source area is between $4200 \mathrm{~m}$ and $5266 \mathrm{M}$. The grassland resources in the source area of the Yellow River are extremely abundant. The grassland covers about $80 \%$ of the area of the source area. It is one of the most important animal husbandry bases in the Qinghai-Tibet Plateau of China (Wang, Li, 2010). The alpine grassland types in the source area of the Yellow River mainly include swamp meadow, alpine meadow, degraded meadow and alpine grassland, etc. Their ecological process has a unique barrier role to protect the ecological security of China and even

\section{East Asia.}

\subsection{Data Acquisition}

UAV low-altitude remote sensing system has become the best way to effectively collect patch information because of its low cost, flexibility, high spatial resolution, high-risk area detection and other advantages (Zang, Sun, 2010). In this study, Phantom 3 Professional miniature integrates aerial Four-rotor vertical takeoff, and landing UAV is used to take photos. The maximum flight altitude of the UAV is over $300 \mathrm{~m}$ at an altitude of 4000 $\mathrm{m}$ on the Qinghai-Tibet Plateau, and its duration is about 23 minutes. The fuselage is equipped with a three-band high-definition light digital camera Sony EXMOR Sensor with a resolution of 12 million pixels and a viewing angle of 94 degrees. At a height of $20 \mathrm{~m}$, the fuselage can reach the ground coverage of $35 \mathrm{~m} * 26 \mathrm{~m}$ and the ground sampling accuracy of about $1 \mathrm{~cm}$. The coverage of collected data pixels ranges from 0 to 255 ( 0 represents bare land, 255 represents vegetation). At the same time, the UAV is equipped with a high-precision self-driving flight control system. This system is based on the SDK software development kit developed by Dajiang Company and the UCMAP software developed by Nanjing Zhebu Company. The software can be used to set working points, flight routes, flight and so on through the graphical interface. Control UAV.

In this study, a white rope is used to frame the boundary of the sample plot in the study area to make the sample plot more precise. By controlling the vertical takeoff of UAV in the center of the sample plot and taking photos vertically downward at a height of $30 \mathrm{~m}$, four working points are selected in the source area of the Yellow River, namely, different alpine grassland types, at each working point. Ten routes are set up at the grassland type, and four groups of aerial photographs of alpine grassland are finally obtained.

\subsection{Extraction of vegetation patches and bare land patches in Alpine Grassland}

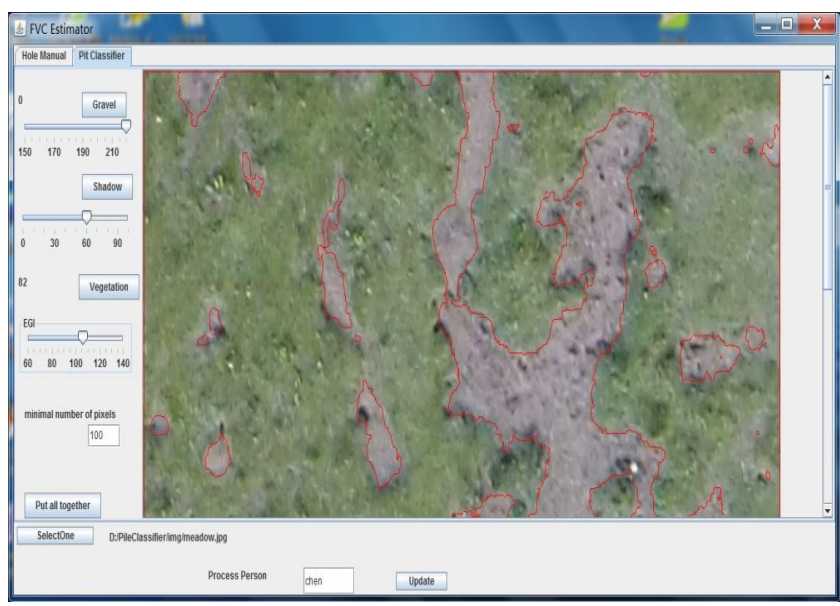

Figure 1. Vegetation patch extraction software interface

In order to extract patch information more effectively, the vegetation patches and bare patches in aerial photographs are extracted by using the vegetation coverage extraction software 
compiled based on Java (Figure 1). Based on the large color difference between vegetation patches and bare patches, the software describes patches by threshold intensity. The threshold index used is EGI. Since the EGI value of vegetation patches in Qinghai-Tibet Plateau ranges from 60 to 140 (Chen, Yi, 2016), the initial value of EGI threshold is set between 60 and 140 to improve the design. The steps of patch extraction are as follows: 1) calculating the EGI value of each pixel in the image; 2) setting an EGI threshold and comparing the EGI value of each pixel in the image with the threshold value. If the EGI value of the pixel is larger than the threshold value, the pixel is regarded as a vegetation patch; otherwise, it is a bare patch; 3) comparing the classification results with the original image; If the classification is accurate, the classification will be completed. If the classification is not accurate, the threshold will be adjusted to jump to 2 until the classification of vegetation patches and bare land patches is accurate. In the extracted images, vegetation patches are represented by white pixels, bare land patches are represented by black pixels, and the extraction results of four grassland types are shown in Figure 2.
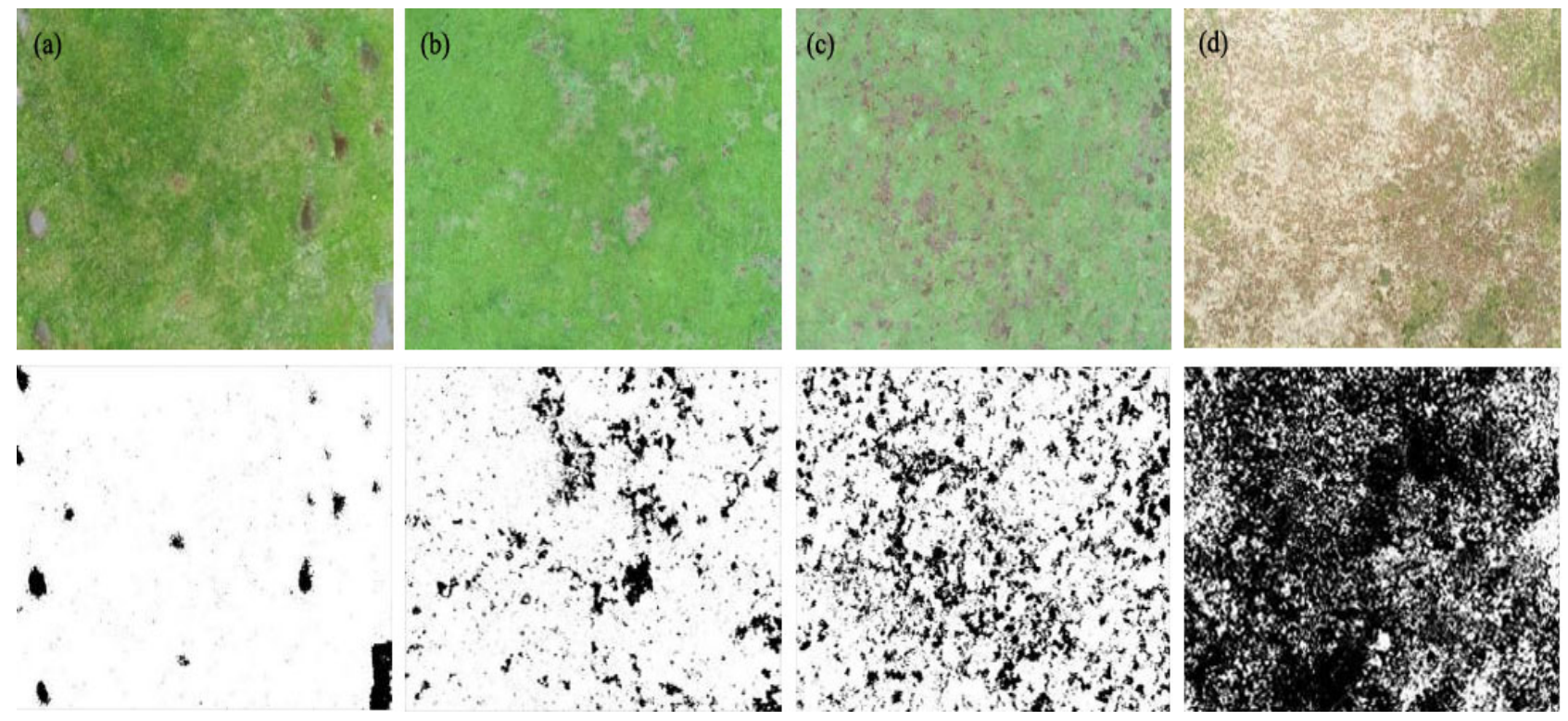

Figure 2. Drawing of patch extraction effect of four grassland types

(a: swamp meadow; b: alpine meadow; c: degraded meadow; $d$ : alpine glassland)

\subsection{Selection of Landscape Index and Its Ecological Significance}

The image of vegetation patches and bare land patches is processed by ArcGIS and imported into Fragstats software. The index of patch type and landscape level is selected (Table 1). In order to study patch structure and fragmentation gradient, patch number (NP) and patch type area (CA) are selected in this paper. In order to study patch aggregation distribution and dominance analysis, contagion degree (CONTAG) and maximum patch area ratio (LPI) are selected in this paper. In order to study the complexity of patch shape, area-weighted shape is selected in this paper. Shape index (AWMSI), area weighted fractal dimension (AWMPFD).Finally, each grassland area sample photo is processed and the corresponding data are imported into the Origin Software for statistical analysis, so as to study the spatial differentiation characteristics of four grassland patches.

\begin{tabular}{llll}
\hline Landscape Index & Formula & Formula description & Ecological Significance \\
$\begin{array}{l}\text { Total area of plaque types } \\
\text { (CA) }\end{array}$ & $C A=\sum_{\mathrm{j}=1}^{n} a_{i j} * \frac{1}{1000}$ & $\begin{array}{l}\text { CA is equal to the sum of all } \\
\text { patches in a patch type (m2), } \\
\text { divided by } 10006 \text { and } \\
\text { converted into hectares }\end{array}$ & $\begin{array}{l}\text { The magnitude of its value } \\
\text { restricts the abundance,quantity, } \\
\text { food chain and the reproduction } \\
\text { of secondary species in } \\
\text { Habitation }\end{array}$ \\
\hline Number of plaques (NP) & $N P=N$ & $\begin{array}{l}\text { N is the total number of } \\
\text { patches in the landscape, and } \\
\text { NP ranges from NP to } 1\end{array}$ & $\begin{array}{l}\text { NP has an impact on many } \\
\text { ecological processes, such as } \\
\text { determining the spatial } \\
\text { distribution characteristics of } \\
\text { various species and their } \\
\text { secondary species in the } \\
\text { landscape }\end{array}$ \\
\hline
\end{tabular}


Fragmentation (PD) $\quad P D=\frac{N}{A} * 1000 * 100$

The proportion of the largest patches in the landscape area (LPI)
$\mathrm{N}$ is the total number of patches in the landscape, $\mathrm{A}$ is the total area of the landscape, in units of $1 / \mathrm{km} 2$ $\mathrm{a}_{\mathrm{ij}}$ represents the area of patch $\mathrm{ij}$; $\mathrm{A}$ is the total area including the internal background of the landscape, and the value range is $0<$ LPI $<1$
Reflecting the number of patches per unit area

\section{It is helpful to determine the} dominant types of landscape, determine the ecological characteristics of dominant species and abundance of internal species in landscape, and reflect the direction and strength of human activities

Aggregation degree (AI) $A I=\left[\sum_{i=1}^{m}\left(\frac{g_{i i}}{\max g_{i i}}\right) p_{i}\right] * 100$

$\mathrm{g}_{\mathrm{ii}} 、 \operatorname{maxg}_{\mathrm{ii}}$ is the number of nodes and the maximum number of nodes between patch type I pixels based on haploid method, and PI is the area proportion of patch type I in landscape

It measures the maximum possible number of similar nodes in a given landscape composition, reflecting the degree of patch aggregation indirectly reflects the strength of the ecosystem

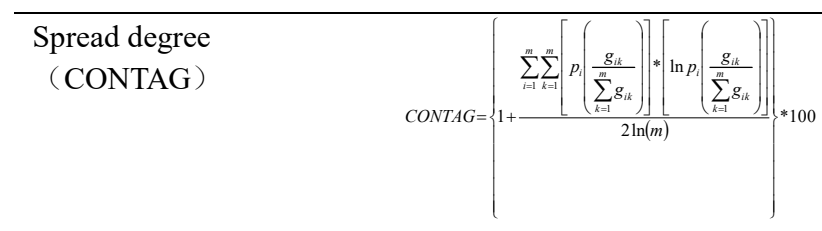

When the value is small, it indicates that there are many small patches in the landscape tending to be 100 , which indicates that there are dominant patch types with high connectivity in the landscape

$\begin{aligned} & \text { Area Weighted Shape } \\ & \text { Index (AWMSI) }\end{aligned} \quad A W M S I=\sum_{\mathrm{i}=1}^{m} \sum_{j=1}^{m}\left[\left(\frac{0.25 P_{i j}}{\sqrt{a_{i j}}}\right)\left(\frac{a_{i j}}{A}\right)\right]$
The sum equal to the average shape factor of each patch type multiplied by the weight of patch area to landscape area

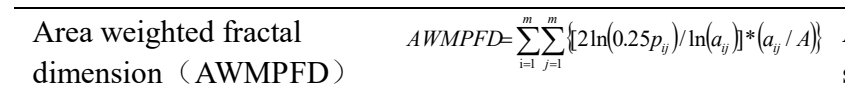

AWMPFD $=1$ represents the simplest square or circle in shape, and AIMPFD = 2 represents the most complex patch type in circumference
It describes the agglomeration degree or extension trend of different patch types in the landscape. Because this index contains spatial information, it is one of the most important indexes to describe landscape pattern

Measuring the complexity of landscape spatial pattern, patch shape affects animal migration, foraging and other activities, affecting plant planting and production efficiency

It reflects the overall characteristics of landscape pattern and the impact of human activities on landscape pattern. Generally speaking, the fractal dimension of natural landscape with little disturbance from human activities is high

Table 1. Statistical table of landscape

\subsection{Ecological Risk Analysis}

In order to establish a relationship between the landscape patch structure of Alpine Grassland in the source area of the Yellow River and the ecological risk in the region, the ecology risk index (ERI) is introduced to better reflect the changes of ecological risk caused by the succession of patch spatial structure (Peng, Dang, 2015). The calculation formulas are as follows:

$$
E R I=\sum_{\mathrm{i}=1}^{m} \frac{S_{i} X_{i}}{S}
$$

where $\quad E R I=$ the ecological risk index

$\mathrm{S}_{\mathrm{i}}=$ the type area in the first place

$\mathrm{S}=$ the total area
$\mathrm{Xi}$ is the ecological intensity parameter reflected by the type in the second place. Its value refers to the risk intensity parameter of different land use landscape types in Shaanxi Province of Liu Yinpigeon, and the parameter $\mathrm{Xi}=0.110$ (Liu, 2011) used in this paper.

\section{RESULTS AND ANALYSIS}

\subsection{Patch Extraction from Aerial Images}

UAV acquisition of high-resolution remote sensing images has become an important means of acquiring spatial data. Its debugging is simple, performance is reliable, and the system using GPS navigation has a high accuracy (Zang, Sun, 2010). The research of vegetation patches and bare land patches by UAV aerial photography technology effectively avoids the lack 
of accuracy of satellite remote sensing data which can not recognize small patches. It reflects the feasibility of aerial photography patches research, and provides a reliable basis for subsequent patch research.

\subsection{Patch Structure and Fragmentation Gradient Analysis}

\begin{tabular}{ccc}
\hline Grassland Type & Patch Number (Number) & Proportion (\%) \\
\hline Swamp meadow & 198482 & 47.4 \\
Alpine meadow & 358052 & 31.6 \\
Degraded meadow & 836882 & 7.5 \\
Alpine grassland & 1258156 & 13.5 \\
Total & 2651572 & 100 \\
\hline
\end{tabular}

Table 2. Statistical table of the number of patches on the Qinghai-Tibet plateau

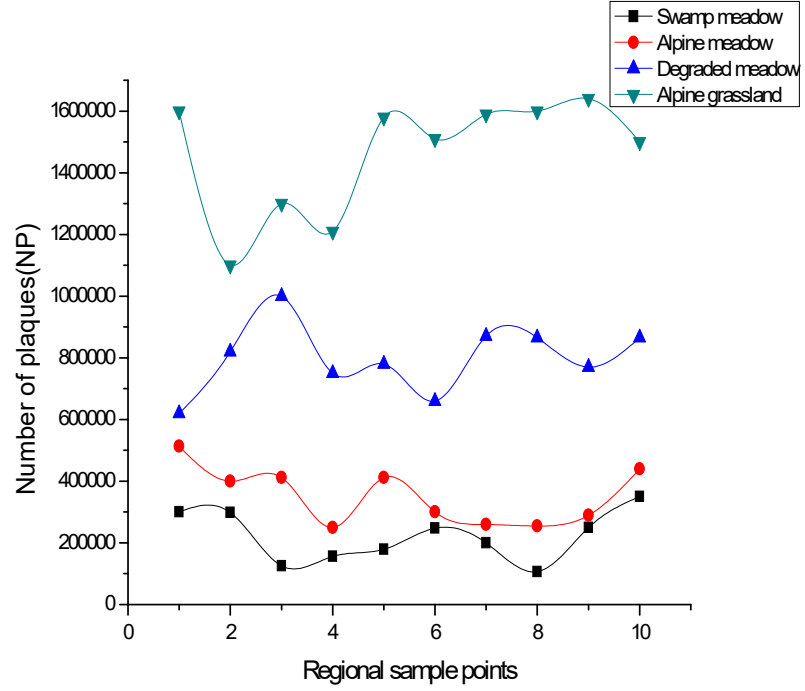

Figure 3. Curves of the number of patches of sample points in each region of the four grassland types

Combining with the schematic map of patch extraction effect of four grassland types and Table 2, there are 2651572 patches in the Qinghai-Tibet Plateau when the landscape area of four grasslands is fixed. Among them, 198482 are giant patches in swamp meadow, 358052 in alpine meadow and 836882 are medium patches in degraded meadow. There are 1258156 small patches in the alpine grassland. The number of patches along the sequence of swamp meadow, alpine meadow, degraded meadow and alpine grassland ranged from small to large. According to the number of patches, the proportion of patches of grassland types, and figure 3 , it can be seen that the alpine grassland accounts for the largest proportion of patches, $47.4 \%$, nearly half of the patches. The number of patches accounts for the most prominent advantage, followed by degraded meadows, which accounts for $31.6 \%$. The number of patches on the map is in positive phase with the fragmentation of landscape. Guan, it can be concluded that the patch fragmentation of these two grassland types is relatively high, which is seriously disturbed by human activities, and then splits into more patches. The proportion of swamp meadow and alpine meadow is equal, $7.5 \%$ and $13.5 \%$ respectively. They are evenly distributed, less disturbed by human activities and less fragmented, so they should be developed in the future. The protection and planning of this type of grassland should be strengthened in utilization.
On the scale of type patches, from Figure 4, the vegetation patch area of swamp meadow, alpine meadow and degraded meadow decreased slowly in turn. The vegetation patch area of alpine grassland is the smallest, almost close to desert, while the bare land patch area is inversely proportional to the vegetation patch area. Combined with landscape ecology, patch area determines patch stability. The smaller the vegetation patch area, the weaker the stability of this type of grassland and the worse the ability to resist the change of ecological environment, the alpine grassland shows a high degree of vegetation sparsity, grassland desertification, and the worst anti-interference ability. If with human activities and grassland animal husbandry. The desertification area of alpine grassland will gradually expand with the intensification of grazing (Ma, 2013)

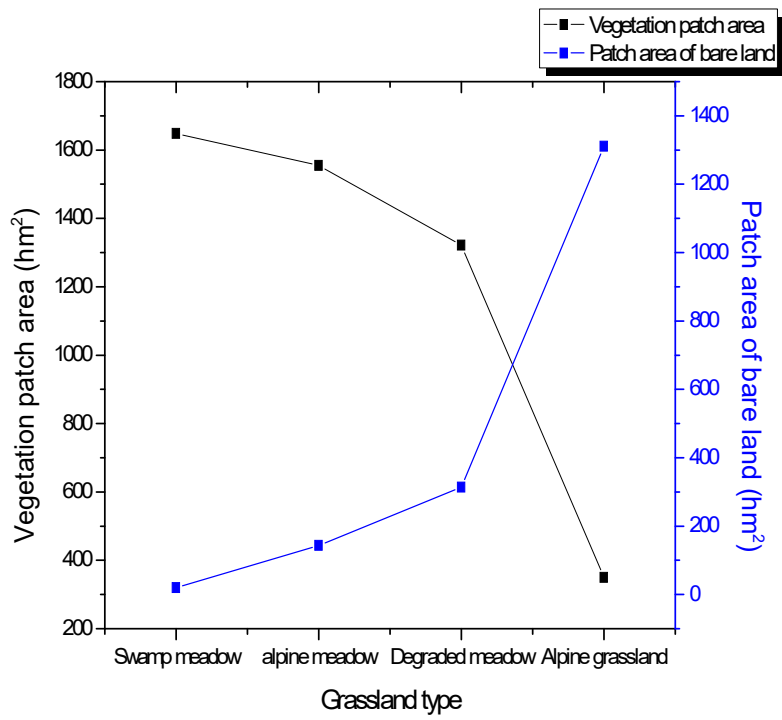

Figure 4. Area curves of four grassland patch types

\subsection{Patch Aggregation Distribution and Dominance Analysis}

As shown in Figure 5, the degree of spread reflects the aggregation and distribution of patches. The degree of spread of each grassland type can be seen from the map: swamp meadow $>$ alpine meadow $>$ degraded meadow $>$ alpine grassland. Combining with the analysis of patch number, it can be seen that the number of degraded meadow with small patches and alpine grassland with medium patches are 
relatively large. When the plot area is fixed, the patches of these two grassland types have a lower spreading degree. It can be concluded that the patches are small and scattered, the aggregation degree is low, the patches are more susceptible to external interference, and the compressive capacity is poor, which will only gradually desertify with the passage of time; the number of two types of grasslands, the swamp meadow with huge patches and the alpine meadow with large patches. Less, but the spread between patches is higher, the distance between patches and patches is closer, the connectivity between patches is higher, the biological energy, material exchange and ecological succession effect between patches is good, and the patches have a good degree of aggregation.

The maximum patch index reflects the uniform dominance degree of landscape area. Marsh meadow has the highest LPI, 94.29741, and alpine grassland has the lowest LPI, which indicates that large patches are constantly fragmented and fragmented. From the LPI of vegetation types, bare land types and landscape types(in table 3 ), it can be seen that the maximum patch index of four grassland vegetation types, swamp meadow, alpine meadow, degraded meadow and alpine grassland, decreases in turn, while bare land type decreases in turn. The spatial characteristics of patches in alpine grasslands are bad. The maximum vegetation patch index is the smallest, which is only 4.9607. On the contrary, the maximum patch index in bare land is 71.0394, and the dominance among landscape patches is very low.

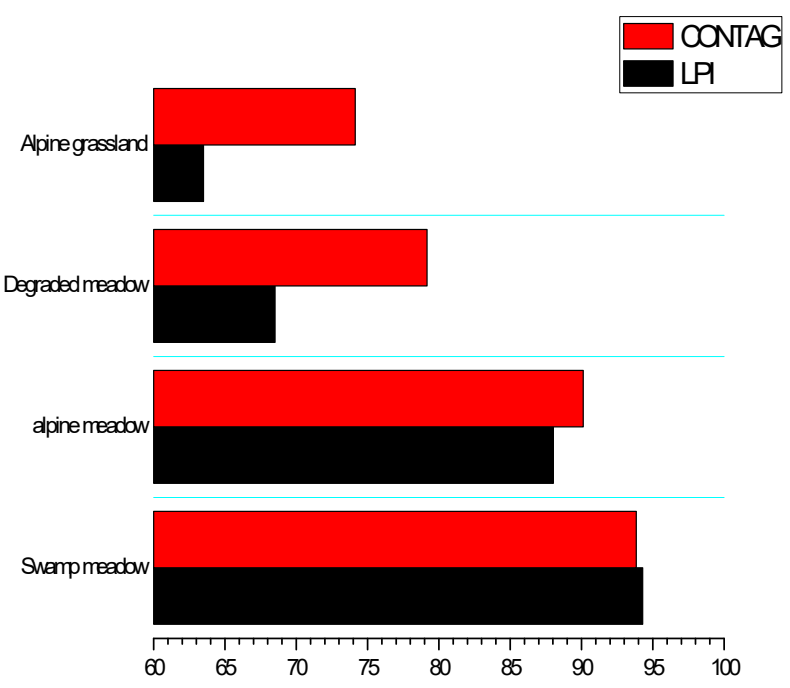

Figure 5. CONTAG and LPI of four grassland patch types

\begin{tabular}{cccc}
\hline Grassland Type & LPI of Vegetation Type & LPI of bare land type & LPI of Landscape \\
\hline Swamp meadow & 97.8647 & 0.6691 & 94.29741 \\
Alpine meadow & 87.4649 & 0.6506 & 88.02931 \\
Degraded meadow & 73.8257 & 0.8681 & 68.50843 \\
Alpine grassland & 4.9607 & 71.0394 & 63.49458 \\
\hline
\end{tabular}

Table 3. Statistical table of maximum patch index of four kind of grassland

\subsection{Analysis of Patch Shape Complexity}

The area-weighted shape index and area-weighted fractal dimension are selected to analyze the shape characteristics of four grassland landscapes, which have good correlation and represent the complexity of patch shape. The higher the value, the more complex the shape is, the more separate the patches are. The area-weighted fractal dimension reflects the complexity of patch boundary and landscape fragmentation. As shown in the figure 6 , the area-weighted fractal dimension increases in turn, which indicates that all four grasslands are affected by human activities and aggravated to varying degrees. The fractal dimension of degraded meadows and alpine grasslands is relatively high, which are 1.58699 and 1.6059, respectively. This shows that this type of grassland is characterized by its high fractal dimension The fractal dimension of swamp meadow and alpine meadow is lower, which are 1.452342 and 1.50167 , respectively. It can be seen that the two grassland patch boundary folding degree is low and the landscape fragmentation degree is low.

The area-weighted average index reflects the complexity of landscape spatial pattern. The shape index of small patch alpine grassland and medium patch degraded meadow is larger, 155.014 and 112.6802 , respectively. It shows that the

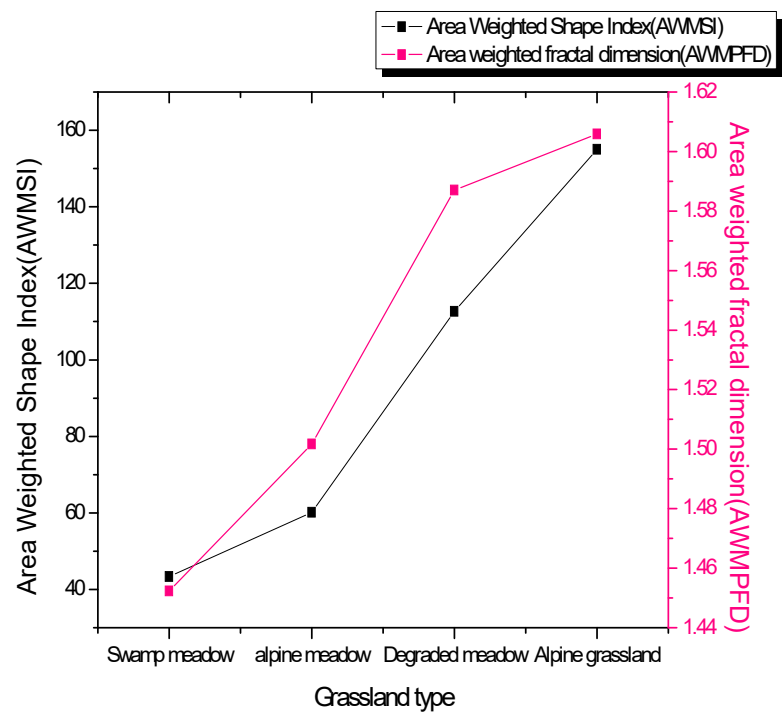

Figure 6. AWMSI and AWMPFD of four kinds of grassland

shape of patch deviates from regular shape, the ratio of length to width is larger, the shape structure is extremely loose, and it is carried out with the outside environment. The exchange of substance, energy and organism is frequent, which 
increases a large number of animal migration, foraging and other activities. The grassland succession is relatively rapid, affecting the dynamic development of the landscape, thus forming a complex spatial pattern, indicating that there are high-risk ecological risks in the alpine grassland. Secondly, the alpine meadow with large patches, 60.1862, has regular shape, but the degree of deviation between patches is obvious, which belongs to the type of moderately compact patches; the marsh meadow with the smallest shape index is 43.35521, which indicates that the patches with large patches are relatively compact in shape and less disturbed by the outside world. It can form a good energy cycle by itself.

\subsection{Ecological Risk Analysis of Alpine Grassland in the Source Area of the Yellow River}

\begin{tabular}{cc}
\hline Grassland Type & Average ecological risk intensity index \\
\hline Swamp meadow & 0.001 \\
Alpine meadow & 0.009 \\
Degraded meadow & 0.019 \\
Alpine grassland & 0.08 \\
\hline
\end{tabular}

Table 4. Statistical table of average ecological risk intensity index of alpine grassland

Formula (1) is used to calculate the ecological risk intensity index of Alpine Grassland in the source area of the Yellow River (Table 4). The average ecological risk intensity index is swamp meadow $<$ alpine meadow $<$ degraded meadow $<$ alpine grassland. The Alpine Grassland in the source area of the Yellow River is in the dangerous period of grassland

\section{DISCUSSION}

Studying the spatial differentiation characteristics of grassland patches is the most direct and practical method for assessing ecosystem status (Kefi, Alados, 2010). It is closely related to ecosystem function and promotes the understanding of ecological phenomena covered by spatial pattern representation (Meloni, Granzotti, 2017), so as to better understand the succession characteristics of patches in alpine grassland degradation process (Chu, Wang, 2014). In the region where this study is located, the ecological pressure resistance is poor and the aggregation scale gradually decreases, thus forming a patchy spatial pattern. As the bottom structure of ecosystem, grassland patches and bare land patches are affected by precipitation and temperature in space.Hydrothermal conditions are the main abiotic factors affecting the spatial distribution of grassland patches and bare land patches (Chen, Wang, 2009). Precipitation and temperature can influence the patch succession process of grassland growth cycle and growth rate through effective accumulated temperature and available water. Generally speaking, the spatial heterogeneity of hydrothermal conditions on a large scale has an important influence on the spatial distribution characteristics of grassland patches and bare land patches (Zhang, 2017). In nature, rodent gnawing is also the cause of patch spatial differentiation. The occurrence of grassland rodent damage is one of the important signs of grassland degradation and desertification (Li, Yuan, 2018). Because of the imperfect management of Alpine Grassland in the source area of the Yellow River, grassland patches will be affected by human factors in the outside world. The impact of farmer grazing on landscape ecology is enormous, which plays a decisive role in the degradation of alpine grassland in the source area of the Yellow River. Therefore, it is very important to study the patch succession process of alpine grassland in the source area of the Yellow degradation. A large number of grasslands are transformed into bare land. The fragmentation is increasing, the connectivity between patches is low, and the stability of regional natural ecosystem is low, which leads to the increase of ecological risk intensity.

River, which can provide a reliable scientific basis for the restoration and reconstruction of

Alpine degraded ecosystem in the source area of the Yellow River.

Through this study, we can find that the four selected grassland types are the process of patch succession in ecosystem. In the first stage of degradation succession, swamp meadow succession is alpine meadow. There is no obvious change in the total grassland patches, the number of patches increases, the degree of aggregation between patches decreases, and the shape of patches changes from regular to complex. In the second stage of degradation succession, alpine meadow succession is degraded meadow, the number of original grassland patches is significantly increased, the degree of fragmentation is significantly increased, the distance of patches tends to be separated, the shape of patches tends to be complex and diverse, and the connectivity is urgent. The degree of ecological dominance declined sharply. From a series of landscape index changes, we can see that in this succession stage, due to excessive grazing and environmental changes, grassland continues to degenerate, and the ecological function of alpine grassland is further damaged. In the third stage of degradation succession, degraded meadow succession is alpine grassland, bare land patches occupy grassland in a large area, alpine grassland is in a serious degradation stage, the landscape index changes sharply, and the ecological risk index increases from 0.019 to 0.08 . A large number of bald patches appear in grassland, soil moisture and nutrients decline, and grassland is serious. Degradation, rodent increase, this succession stage is an irrecoverable ecological period. There are some deficiencies in this study. The study area lacks long-term continuous monitoring data of alpine grassland, which is difficult to accurately reflect the spatial distribution characteristics of patches in the region.However, the research results have certain 
reference value.In addition, the patch spatial differentiation characteristics of Alpine Grassland in the source area of the Yellow River and the influence mechanism of hydrothermal factors need further confirmation.

\section{ACKNOWLEDGEMENTS}

This study was supported by the National Natural Science Foundation of China (41801030, 41901370, 41961065); Guangxi Natural Science Foundation (2018GXNSFBA281054, 2018GXNSFBA281075, 2017GXNSFDA198016); Research Foundation of Guilin University of Technology (GUTQDJJ2017069); the BaGuiScholars program of the provincial government of Guangxi (Guoqing Zhou).

\section{REFERENCES}

Bolger, D., Alberts, A., Soule, M.E., 1991.Occurrence patterns of bird species in habitat fragments:samples, extinction, and nested species subsets. The American Naturalist, 137:155-165.

Chen, J., Yi, S., Qin, Y., et al., 2016. Improving estimates of fractional vegetation cover based on UAV in alpine grassland on the Qinghai-Tibetan Plateau. International Journal of Remote Sensing, (8): 1922-1936.

Chen, X.Q., Wang, H., 2009. Spatial and Temporal Changes of Vegetation Belt and Vegetation Coverage in Inner Mongolia from 1982 to 2003. Journal of Geography, 64(1): 84-94.

Chu, G., Wang, M., Zhang, S., 2014. Spatial patterns and associations of dominant woody species in desert-oasis ecotone of South Junggar Basin, NW China. Journal of Plant Interactions, 9(1): 738-744.

Irvine, M.A., Bull, J.C., Keeling, M.J., 2015. Aggregation dynamics explain vegetation patch-size distributions. theoretical population biology, 12.001.

Kefi, S., Alados, C.L., Chaves, R.C.G., 2010. Is the patch size distribution of vegetation a suitable indicator of desertification.processes.Comment.Ecology,91(12): 3739-3742.

Kefi, S., Rietkerk, M., Roy, M., Franc, A., 2010. Robust scaling in ecosystems and the meltdown of patch size distributions before extinction. Journal Citation Reports, $10.1111 /$ j.1461-0248.

Li, C.L., 2018. Spatial Distribution Patterns of Cultivated Land in Parallel Ridge and Valley Area of Eastern Sichuan. Chongqing Normal University.

Li, Y.N., Yuan, S., Fu, H.P., et al, 2018. Relationship between Rodent Density and Herbage Loss in Typical Steppe. Journal of Mammals, 38(04):369-376.

Liu, Y.G., 2011. Ecological Risk Analysis of Shaanxi Province Based on Land Use. Bulletin of Soil and Water Conservation, 31(03):180-184+189.
Ma, Q.K., 2013. Causes and Analysis of Grassland Degradation in Alpine Steppe. Qinghai Prataculture, 22(02):23-25.

Meloni, F., Granzotti, C.R.F., Bautista, S., 2017. Scale dependence and patch size distribution_ clarifying patch patterns in Mediterranean drylands.Ecosphere, 08(02):e01690.

Pan, D., Domon, G., Marceau, D., 2001. Spatial pattern of coniferous and deciduous forest patches in an Eastern North America agricultural landscape. the influence of land use and physical attributes.Landscape Ecology, 16:99-110.

Peng, J., Dang, Q.X., Liu, Y.X., et al, 2015. Research Progress and Prospect of Landscape Ecological Risk Assessment. Journal of Geography, 70(04):664-677.

Wang, G.X., Li, Y.S., Wang, Y.B., et al, 2010. Surface Processes and Environmental Changes in the River Source Area of the Qinghai-Tibet Plateau. Beijing: Science Press.

Wang, X.L., Xiao, D.N., Bu, R.C., et al, 1997. Analysis of Landscape Patterns of Wetlands in Liaohe Delta. Journal of Ecology, (03):317-323.

Zang, K., Sun, Y.H., Li, J., et al., 2010. Application of Micro UAV Remote Sensing System in Wenchuan Earthquake. Journal of Natural Disasters, 19(3): 162-166.

Zhang, Z.Y.,2017. Spatial Distribution Characteristics of Vegetation-Soil in Temperate Sparse Forest and Grassland Ecosystem in Inner Mongolia. Chinese Academy of Forestry Sciences.

Zhao, X.Q., Ma, Y.T., Zhou, H.K., et al, 2001. Restoration and Sustainable Management of Degraded Ecosystem in the Source Area of the Three Rivers. Beijing: Science Press.

Zheng, W., 2009. Study on Response Mechanism of Grassland Plant Diversity to Human Disturbance in Kanas Tourist Area of Xinjiang. Xinjiang Agricultural University. 